\title{
PENGARUH BEBERAPA DOSIS CMA (Cendawan Mikoriza Arbuskula) TERHADAP PERTUMBUHAN VEGETATIF TANAMAN GANDUM (Triticum aestivum L)
}

\author{
Muhammad Nizar Hanafiah Nasution ${ }^{1^{*}}$, Rasmita Adelina Harahap ${ }^{\left.2^{*}\right)}$ \\ ${ }^{1,2 *}$ Program Studi Agroteknologi Fakultas Pertanian Universitas Graha Nusantara \\ Padangsidimpuan Sumatera Utara Indonesia \\ Email : Nizarhanafiah.12@gmail.com
}

\begin{abstract}
ABSTRAK
Pengembangan tanaman gandum harus divariasikan dengan banyak metode salah satunya dengan pemberian pupuk hayati CMA (Cendawan Mikoriza Arbuskula). Tujuan penelitian ini adalah untuk melihat pengaruh dosis CMA terhadap pertumbuhan vegetatif tanaman gandum. Rancangan percobaan yang digunakan dalam penelitian ini adalah RAK (Rancangan Acak Kelompok) dengan empat perlakuan dosis Mikoriza dengan dosis 0, 15, 30 dan 45 gram dan tiga ulangan. Beberapa dosis CMA (Cendawan Mikoriza Arbuskula) yang diberikan belum memberikan pengaruh signifikan terhadap pertumbuhan vegetatif tanaman gandum.
\end{abstract}

Kata kunci : Gandum, mikoriza.

\section{PENDAHULUAN}

Pengembangan gandum di Indonesia diarahkan kepada untuk daerah tropis, toleran panas dan umur genjah. Pengembangan tersebut harus divariasikan dengan banyak metode, ketinggian tempat yang bervariasi misalnya dataran medium hingga dataran rendah. Metode lain bisa juga dengan jarak tanam, pemberian pupuk organik, sintetik, POC , pupuk hayati seperti mikoriza, dll. Pola yang bervariasi tersebut diharapkan mampu menghasilkan gandum hasil negeri sendiri dengan kualitas yang bagus dan dapat dimanfaatkan oleh masyarakat, sehingga tidak tergantung terhadap impor gandum.

Salah satu pupuk hayati yang sangat potensial untuk dikembangkan adalah Mikoriza, pupuk hayati jenis ini merupakan simbiosis antara jamur dengan akar tanaman. Jumlah mikoriza 
sangat melimpah di alam dan ditemukan hampir $80 \%$ dapat bersimbiosis dengan tumbuhan angiospermae, serta berperan penting dalam meningkatkan pertumbuhan tanaman agrikultur, hortikultura, dan tanaman hutan. Secara umum mikoriza tergolong dalam dua tipe yaitu ektomikoriza dan endomikoriza atau mikoriza arbuskula. Mikoriza arbuskula banyak dijumpai pada sebagian besar tanaman (Dewi, 2007).

Tanaman gandum merupakan tanaman yang baru untuk masyarakat Tabagsel, karena pada umumnya hampir semua kalangan belum mengetahui bentuk morfologi tanaman ini. Kalangan akademisi juga belum tahu pasti bentuk dari tanaman ini gandum ini di wilayah Tabagsel. Secara topografi dan letak geografis Tabagsel, potensi pengembangan gandum cukup menjanjikan, jadi diperlukan kiranya potensi tanah di Tabagsel untuk penanaman gandum diuji. Salah satu daerah tersebut adalah Desa Pintu Langit Kecamatan Padangsidimpuan Angkola Julu dengan ketinggian 700 m dpl. Tujuan penelitian ini adalah untuk melihat pengaruh dosis CMA terhadap pertumbuhan vegetatif tanaman gandum.

\section{BAHAN DAN METODE}

Penelitian telah dilaksanakan di Desa Pintu Langit Jae Kecamatan Padangsidimpuan Angkola Julu dengan ketinggian $\pm 700 \mathrm{~m}$ dpl, Kota Padangsidimpuan. Bahan yang akan digunakan dalam penelitian ini adalah benih gandum varietas Dewata, Rancangan percobaan yang digunakan dalam penelitian ini adalah RAK (Rancangan Acak Kelompok) dengan empat perlakuan dosis Mikoriza dengan dosis 0,15,30 dan 45 gram dan tiga ulangan . Alat-alat yang digunakan adalah mesin bajak, cangkul, pancang, meteran, tali, camera digital, dan alat - alat tulis. Variabel respon yang diamati meliputi tinggi tanaman, jumlah anakan total, jumlah anakan produktif, umur keluar berbunga. 
HASIL DAN PEMBAHASAN

Tabel 1.Variabel respon dosis CMA tanaman gandum (Tinggi tanaman, jumlah anakan total, jumlah anakan produktif dan umur keluar bunga).

\begin{tabular}{|c|c|c|c|c|}
\hline \multirow{2}{*}{$\begin{array}{c}\text { Dosis CMA } \\
\text { (Cendawan } \\
\begin{array}{c}\text { Mikoriza } \\
\text { Arbuskula) }\end{array}\end{array}$} & $\begin{array}{c}\text { Tinggi } \\
\text { tanaman (cm) }\end{array}$ & $\begin{array}{c}\text { Jumlah } \\
\text { anakan total } \\
\text { (batang) }\end{array}$ & $\begin{array}{c}\text { Jumlah anakan } \\
\text { produktif } \\
\text { (batang) }\end{array}$ & $\begin{array}{c}\text { Umur keluar } \\
\text { bunga (HST) }\end{array}$ \\
\hline 0 gram & 67.86 & 13.60 & 10.26 & 62 \\
\hline 15 gram & 68.86 & 12.73 & 9.26 & 62 \\
\hline 30 gram & 65.33 & 12.78 & 9.91 & 62 \\
\hline 45 gram & 64.00 & 9.50 & 6.25 & 62 \\
\hline
\end{tabular}

Pertumbuhan vegetatif adalah awal dari pertumbuhan tanaman, pertumbuhan vegetatif mempengaruhi pertumbuhan selanjutnya atau prtumbuhan generatif. Pada Tabel 1 dapat dilihat bahwa tanaman tertinggi adalah varietas dosis 15 gram yaitu $68.86 \mathrm{~cm}$. Hasil penelitian Nur, et al., (2010) juga menunjukkan bahwa tinggi tanaman akhir (TTA) pada beberapa genotipe gandum yang diadaptasikan didataran tinggi $>1000 \mathrm{~m}$ dpl berkisar antara 56,57 cm - 77,33 cm. Hasil penelitian Stroke et al (1971) menunjukkan bahwa gandum yang ditanam di daerah subtropics mencapai $120 \mathrm{~cm}$, keragaman tinggi gandum pada penelitian cukup rendah jika dibandingkan dengan penelitian tersebut. Malik (2011) menyatakan bahwa tinggi tanaman gandum dipengaruhi oleh sifat genetik, Rachmadhani et al (2017) menyatakan bahwa ketinggian tempat tanam memberi pengaruh positif terhadap tinggi tanaman, semakin tinggi tempat tanam semakin meningkat pula tinggi tanaman.

Jumlah anakan total pada berbagai dosis CMA hampir sama dengan tanpa perlakuan CMA, anakan tertinggi adalah tanpa perlakuan mikoriza. Berdasarkan deskripsi tanaman gandum varietas dewata efektif pada ketinggian $1000 \mathrm{~m}$ dpl sementara lokasi penelitian hanya pada ketinggian $700 \mathrm{~m}$ dpl. Anakan total akan berpengaruh terhadap anakan produktif, jumlah anakan produktif tertinggi masih terdapat pada yang tanpa perlakuan CMA. Jumlah anakan produktif sekitar $80 \%$ artinya anakan produktif cukup bagus karena akan berpengaruh 
terhadap hasil tanaman gandum. Hasil yang didapatkan cukup tinggi jika dibandingkan anakan produktif Novrika et al (2016) yang hanya memperoleh anakan rata-rata 0.01-039 saja.

Umur keluar berbunga pada deskripsi tanaman gandum varietas dewata adalah 55 HST pada dataran rendah 400-800 m dpl, hasil pada Tabel hampir sejalan untuk semua dosis mikoriza yaitu dengan umur berbunga 62 HST. Umur panen akan ditentukan dari umur berbunganya semakin cepat umur berbunga maka akan semakin cepat umur panen.

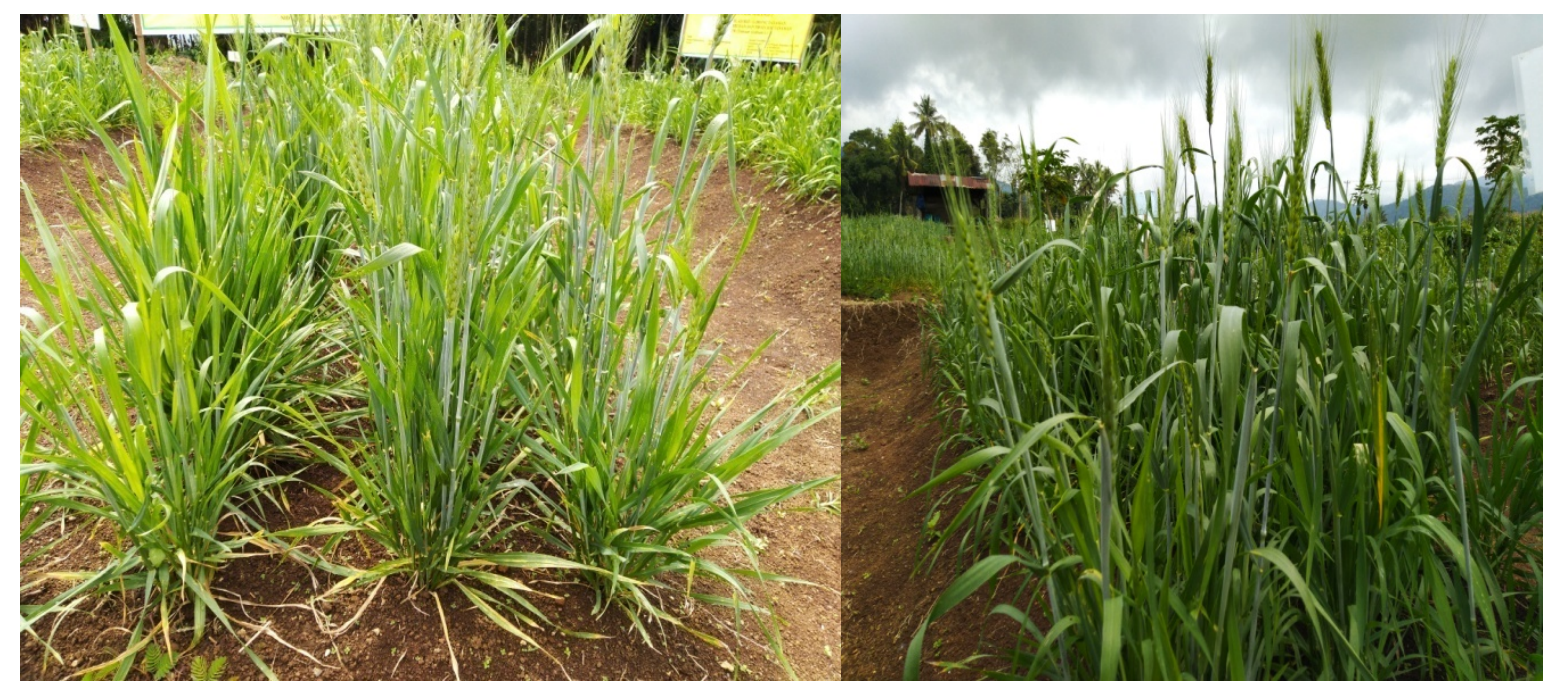

\section{Gambar 1. Tanaman Gandum Umur 60 HST}

Gambar 1 diatas merupakan Morfologi tanaman gandum umur 60 HST (Hari Setelah Tanam). Jumlah anakan produktif yang muncul mempengaruhi jumlah malai. Setiap anakan berpotensi menghasilkan satu malai. Jumlah anakan produktif berpengaruh langsung terhadap hasil tanaman sehingga jumlah anakan produktif dapat dijadikan kriterian seleksi untuk mendapatkan genotif gandum yang berpotensi tinggi. Jumlah anakan juga termasuk variable yang sangat penting untuk diketahui karena berpengaruh terhadap hasil panen (Suriani et al. 2014).

\section{KESIMPULAN}

Beberapa dosis CMA (Cendawan Mikoriza Arbuskula) yang diberikan belum memberikan pengaruh signifikan terhadap pertumbuhan vegetatif tanaman gandum. 


\section{UCAPAN TERIMA KASIH}

Penulis mengucapkan banyak terima kasih terhadap DRPM RISTEKDIKTI yang telah mendanai sehingga terlaksana penelitian ini.

\section{DAFTAR PUSTAKA}

Dewi, A.I.R. 2007. Peran, Prospek dan Kendala Dalam Pemanfaatan Endomikoriza. Jurusan Budidaya Pertanian, Program Studi Agronomi, UNPAD. Jatinangor.

Novrika, D. C. Herison, Fahrrozi. 2016. Korelasi Antar Komponen Pertumbuhan Vegetatif dan Generatif dengan Hasil pada Delapan Belas Genotipe Gandum di Dataran Tinggi. Jurnal Akta Agrosia.Vol 19 (2) : 93-103.

Nur, A. Trikoesoemaningtyas, N. Khumaida, dan S. Sujiprihat. 2010. Phenologi pertumbuhan dan produksi gandum pada lingkungan tropika basah.hlm 188-198. Prosiding Pekan Serealia Nasional. Bogor. Institut Pertanian Bogor.

Rachmadhani S. Damanhuri. Soetopo L. 2017. Uji daya hasil 18 genotif gandum (Triticum aestivum L.) di dataran rendah. Jurnal Produksi Tanaman. 5(8): 1316-1320.

Stroke, J.E. and Mattern. 1971. Result of the first international winter wheat performance nursery. University of Nebraska. 1(83):245-250.

Suriani. Ambo A. Farid. 2014. Uji adaptasi beberapa genotif gandum gandum (Triticum aestivum L.) pada dataran rendah. Budidaya Pertanian, Fakultas Pertanian, Universitas Hasanuddin, Makassar. J. Sains dan Teknologi. 14(3): 269-276. 